\title{
Applying an Artificial Neural Network (ANN) to Assess Soil Salinity and Temperature Variability in Agricultural Areas of a Mountain Catchment
}

\author{
Wiktor Halecki ${ }^{1,2}$, Dariusz Młyński ${ }^{3}$, Marek Ryczek ${ }^{1}$, \\ Edyta Kruk ${ }^{1}$, Artur Radecki-Pawlik ${ }^{4}$ \\ ${ }^{1}$ Department of Land Reclamation and Environmental Development, University of Agriculture, \\ Al. Mickiewicza 24/28, 30-059 Kraków, Poland \\ ${ }^{2}$ Department of Biometry and Forest Productivity, Faculty of Forestry, University of Agriculture in Krakow, \\ Al. 29 Listopada 46, 31-425 Kraków, Poland \\ ${ }^{3}$ Department of Sanitary Engineering and Water Management, University of Agriculture, \\ Mickiewicza 24/28, 30-059 Kraków, Poland \\ ${ }^{4}$ Institute of Structural Mechanics, Faculty of Civil Engineering, Cracow University of Technology, \\ Warszawska Street 24, 31-155 Kraków, Poland
}

Received: 21 January 2017

Accepted: 4 May 2017

\begin{abstract}
Spatial analysis is currently a popular research tool, particularly in studies that focus on soil properties, and it is important for a comprehensive presentation of results by means of spatial statistics techniques. Spatial autocorrelation determines a degree of relationship between variables for two specific spatial units (locations). This relationship is reflected by spatial dependence of investigated soil properties. Moran's I was used as a measure of spatial autocorrelation. Positive spatial autocorrelation was determined for soil salinity (electrical conductivity) and temperature. Thus, the aim of the study was to identify the factors affecting spatial correlation of electrical conductivity (EC) and temperature in farmland and forest-covered areas. A model of artificial neural network was based on salinity, as salinity reduces the amount of nutrients and soil temperature, thus inhibiting plant root growth. Our study revealed that the most effective parameters determining soil temperature were EC and moisture content. The best results in the EC model were achieved for soil moisture content, temperature, and soil texture. Both soil parameters were impacted by catchment land use. Spatial analysis of soil properties and identification of factors affecting their diversity may be helpful in determining proper land use - particularly of sustainable agricultural practices in mountain areas.
\end{abstract}

Keywords: artificial neural networks, land use, multivariate analysis, mountain catchment

*e-mail: wiktor@mailmix.pl 


\section{Introduction}

The values of basic soil parameters at regional, local, or large-area scales may be used to draw conclusions on their spatial variability. However, these relationships are usually neglected, and soil is treated as a homogeneous environment. As a consequence, all measurements of its physical or chemical parameters are usually performed for a single point that is then treated as a reference point for all agrotechnical procedures implemented in a specific area [1-5]. Soil properties may be characterized as either stable (showing low variability over time) or dynamic, depending on external factors such as soil cultivation or weather conditions. The stable properties, represented by soil texture and bulk density, are affected by tillage. The dynamic properties include soil temperature, EC, and moisture content [6-12]. Soil temperature is rarely analyzed in agricultural areas of a mountain catchment. Nevertheless, apart from moisture content and precipitation, it is one of the most important parameters in long-term studies on soil fertility [13]. Soil temperature significantly affects soil-forming processes. It controls metabolic processes and affects weathering of minerals or organic matter degradation [14].

Mapping of EC is useful in studying the relationship between landform and soil [15-16]. Similar to temperature, EC monitoring is also neglected. Soil salinity is usually a local problem caused mostly by anthropogenic and, to a lesser extent, by natural factors. Salinity is a result of disturbed chemical equilibrium of the soil due to a periodic or constant supply of considerable amounts of cations and anions. It is usually manifested by an accumulation of easily soluble salts - generally sulphides and chlorides.
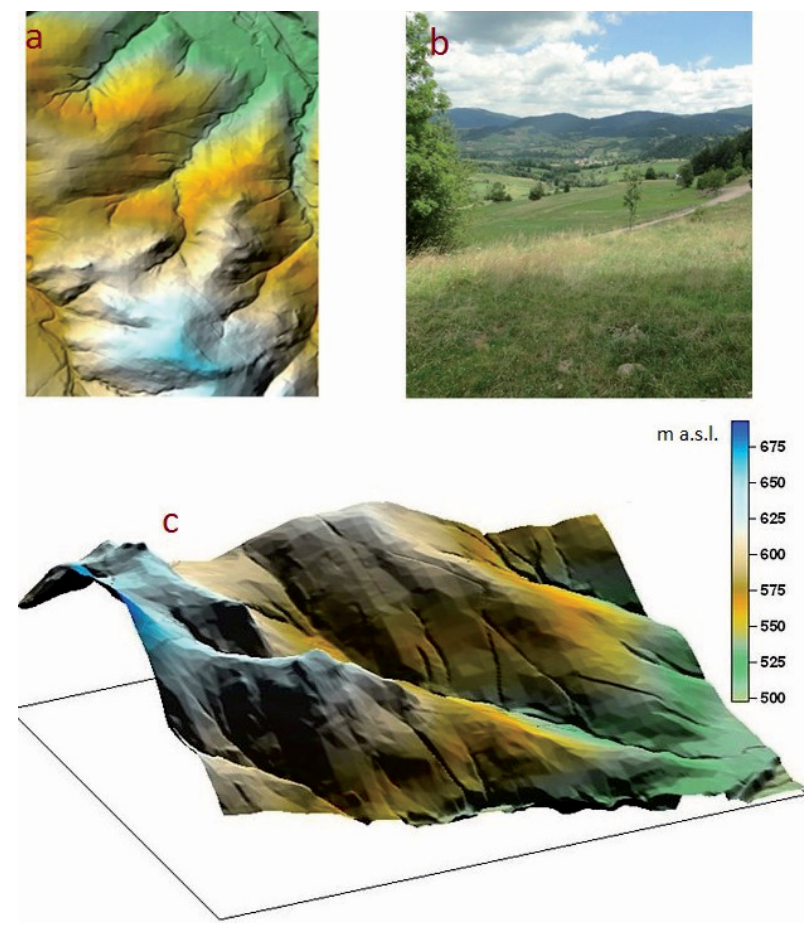

Fig. 1. The catchment of Mątny River: a) relief, b) general overview, c) digital elevation model.
Salinity reduces crop yield by inhibiting soil fertility and plant growth. Its negative impact on plants consists in limiting the availability of water content in soil [1718]. Moisture content is the most often investigated parameter in soil assessment. It is particularly important for crop productivity, as it determines the physiological status of plants and soil microorganisms. However, estimating moisture content is complicated due to a multiplicity of factors that need to be considered, such as its range, percolation, precipitation, or topography [19-20]. Management in agro-ecosystems is required to promote soil carbon (C) sequestration (storage) in agricultural soil, thus assessment of soil quality parameters is essential under different land use forms [21].

Spatial variability of soil parameters, such as bulk density, temperature, salinity, or moisture content significantly affects soil productivity in agricultural and forest areas. Therefore, the aim of this study was to predict by spatial autoregressive model the factors affecting the spatial distribution of soil salinity and temperature using an artificial neural network (ANN).

\section{Materials and Methods}

\section{Study Area and Soil Sampling}

The catchment of Mątny stream (Fig. 1) is located in the External Western Carpathians. The area $\left(1.5 \mathrm{~km}^{2}\right)$ is dominated by meadow, farmland, and forest [22-23]. Soil moisture content, soil temperature, and salinity (electrical conductivity, EC) were measure in 160 study plots by means of a TDR device, which allows for noninvasive, precise, and fully automatic measurements of water content in the soil. The method evaluates volumetric soil moisture based on its relative permittivity without disturbing the soil structure. The results of soil moisture were recorded as a percentage of water in the soil (percent volume). Basic soil properties were described in our previous paper [24].

The soil samples were collected from a top layer of the soil $(0$ to $25 \mathrm{~cm})$ in 80 selected study plots. Metal cylinders $(100 \mathrm{ml})$ had been cleaned and weighed before sampling. The soil from the cylinders was dried at $105^{\circ} \mathrm{C}$, and the soil from plastic bags was sieved through a $2 \mathrm{~mm}$ mesh sieve at room temperature. Soil texture was determined using the method developed by Casagrande in Prószyński's modification. Bulk density (undisturbed natural structure) was determined in volumetric samples of soil maximally saturated with water.

\section{Statistical Analysis}

The investigated soil parameters were characterized by the following descriptive statistics: measures of location minimum, median $(M)$, and maximum values; measures of dispersion - standard deviation $(s)$ and coefficient of variation $\left(V_{s}\right)$; and measures of shape - skewness (Ske) and kurtosis (Kurt). 
Histograms and empirical cumulative distributions were determined for each of the analyzed soil parameters. The number of intervals $\left(L_{k}\right)$ and their width $(\Delta)$ were computed according to the formulas published by Mucha [25]:

$$
L_{k} \approx 5 \cdot \log N
$$

...where $\mathrm{N}$ is the number of data in the observation sequence.

$$
\Delta=\frac{\mathrm{S}_{\max }-\mathrm{S}_{\min }}{\mathrm{L}_{\mathrm{k}}}
$$

...where $\mathrm{S}_{\max }$ is the maximum value of the investigated soil parameter and $\mathrm{S}_{\max }$ is the minimum value of the investigated soil parameter.

Furthermore, the study assessed the effect of land use on changes in the investigated soil properties. The assessment was performed using a non-parametric Kruskal-Wallis test. The inference involved assigning ranks to the ordered elements of all samples and determining the rank sum for each sample. When the differences between the analyzed sums were insignificant, the null hypothesis $\left(\mathrm{H}_{0}\right)$, assuming no significant effect of the analyzed factor on the examined variables was true [26]. In this study, assumption was carried out for $\mathrm{p}<0.05$.

\section{Forecasting Model}

The neural network model in the form of a multilayer perceptron (MLP) was used to generate EC and temperature forecasts in Statistica software (v. 12.5). The network system included input and hidden layers made of five neurons and an output layer with three neurons. Usually all the neurons of the preceding layer were connected to all the neurons of the next layer. Contrary to mathematical and algorithmic methods, the network may be used in many different models without significant modifications. These features may be achieved only by implementation of a proper learning algorithm. Training involves presenting the network with input values together with their respective desired output values. Then the network sets the values of weights so that the answer fits within the margin of error assumed for data modeling. The network taught with a specific data vector will provide results also for data not provided during the learning process.

\section{Spatial Analysis}

Explicative variables (observations) induce a correlation between the error and the lagged variable. Thus, to determine the spatial analysis, spatial autoregressive (SAR) model with lagged dependent variable [27] was used:

$$
\mathrm{Y}=\rho \mathrm{Wy}+\mathrm{X} \beta+\varepsilon
$$

...where $\mathrm{Y}$ is the dependent variable for the spatial model, $\mathrm{y}$ is the value of lagged dependent variable (delayed) in time (explicative variables at site between measurements), $\rho$ is spatial effect coefficient (autocorrelation parameter), Wy is the matrix of spatial weights for the observed variable $y$ (the elements of a row-standardized weight matrix), $\mathrm{X} \beta$ is the matrix of observations for vector of regression coefficient, and $\varepsilon$ is the value of the random component (observation error).

Spatial autoregression and autocorrelation were computed with Spatial Analysis in Macroecology (SAM) software (v. 4.0) [28].

\section{Results and Discussion}

\section{Basic Soil Properties}

The computed values of descriptive statistics for the investigated soil properties were used to describe the dynamics of their changes. The data presented in Table 1 indicate that the greatest bulk density was determined for the forest soils. $\mathrm{V}_{\mathrm{s}}$ values determined for the analyzed areas revealed very low variability. The parameters of its statistical distribution suggested right-side asymmetry of bulk density in forest and agricultural areas and leftskewed asymmetry of bulk density in meadow areas. Contrary to that, the values of kurtosis suggested leptokurtic distribution of this feature in all analyzed

\begin{tabular}{|c|c|c|c|c|c|c|c|}
\hline Land use & Min. & Mean & Max. & $\mathrm{s}$ & $\mathrm{V}_{\mathrm{s}}$ & Sko & Kurt \\
\hline \multicolumn{8}{|c|}{ Bulk density $\left(\mathrm{g} \mathrm{cm}^{-3}\right)$} \\
\hline Meadow & 1.32 & 1.41 & 1.48 & 0.04 & 0.03 & -0.58 & 0.17 \\
\hline Forest & 0.32 & 1.23 & 1.34 & 0.07 & 0.05 & 1.81 & 3.25 \\
\hline $\begin{array}{c}\text { Arable } \\
\text { area }\end{array}$ & 1.28 & 1.32 & 1.38 & 0.03 & 0.02 & 0.54 & 0.51 \\
\hline \multicolumn{8}{|c|}{ Soil temperature $\left({ }^{\circ} \mathrm{C}\right)$} \\
\hline Meadow & 11.8 & 13.3 & 15.2 & 0.78 & 0.06 & 0.48 & -0.55 \\
\hline Forest & 12.6 & 13.1 & 14.2 & 0.65 & 0.05 & 1.93 & 3.77 \\
\hline $\begin{array}{c}\text { Arable } \\
\text { area }\end{array}$ & 12.5 & 14.1 & 15.0 & 0.81 & 0.06 & -1.16 & 0.55 \\
\hline \multicolumn{8}{|c|}{$\mathrm{EC}\left(\mathrm{dS} \mathrm{m}^{-1}\right)$} \\
\hline Meadow & 0.30 & 0.49 & 0.82 & 0.10 & 0.20 & 1.03 & 1.46 \\
\hline Forest & 0.32 & 0.70 & 1.11 & 0.29 & 0.41 & 0.34 & 0.58 \\
\hline $\begin{array}{c}\text { Arable } \\
\text { area }\end{array}$ & 0.41 & 0.65 & 0.98 & 0.20 & 0.31 & 0.29 & -1.56 \\
\hline \multicolumn{8}{|c|}{ Soil moisture (\%) } \\
\hline Meadow & 40.60 & 58.76 & 79.10 & 8.56 & 0.15 & 0.43 & 0.09 \\
\hline Forest & 14.50 & 36.10 & 51.00 & 14.55 & 0.40 & -0.75 & -1.56 \\
\hline $\begin{array}{c}\text { Arable } \\
\text { area }\end{array}$ & 17.10 & 43.84 & 63.20 & 14.44 & 0.33 & -0.68 & 0.22 \\
\hline
\end{tabular}

Table 1. Values of descriptive statistics for the investigated soil properties. 
areas. Similar values of statistical parameters calculated in relation to bulk density were reported by Mzuku et al. [29] for selected soil properties within a 17 ha area in Mississippi, USA. Mean bulk density for the soils in this area was $1.33 \mathrm{~g} \mathrm{~cm}^{-3}$. Similar value was recorded for Mątny stream catchment $\left(1.32 \mathrm{~g} \mathrm{~cm}^{-3}\right)$. Parallel outcomes were also presented by Kilic et al. [30]. Soil temperature analysis demonstrated its highest value for arable lands. Moreover, the investigated areas were characterized by very low variability of soil temperature. Skewness values indicated right-side asymmetry of this parameter for meadows and forests and left-side skewness for arable lands. Kurtosis values indicated leptokurtic distribution of this parameter in forests and arable lands and platykurtic distribution in meadow soils. The highest mean soil salinity was determined in forests, and these areas were also characterized by the greatest variability of this parameter. EC values demonstrated right-side asymmetry in all the investigated types of land. The values of kurtosis suggested leptokurtic distribution of salinity in meadow and forest soils as well as platykurtic distribution in arable lands.

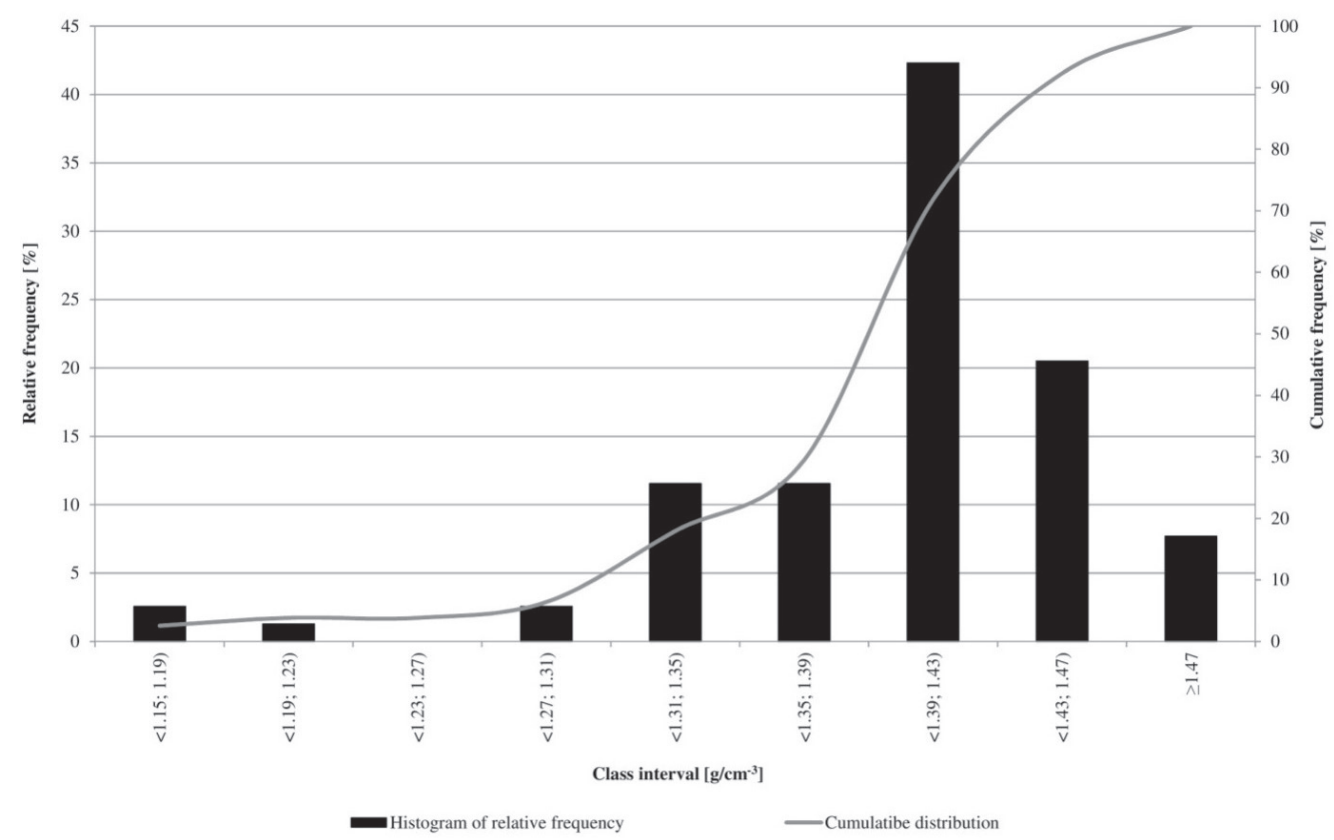

Fig. 2. Histogram of relative frequency and empirical cumulative distribution function for soil bulk density of the Mątny River catchment.

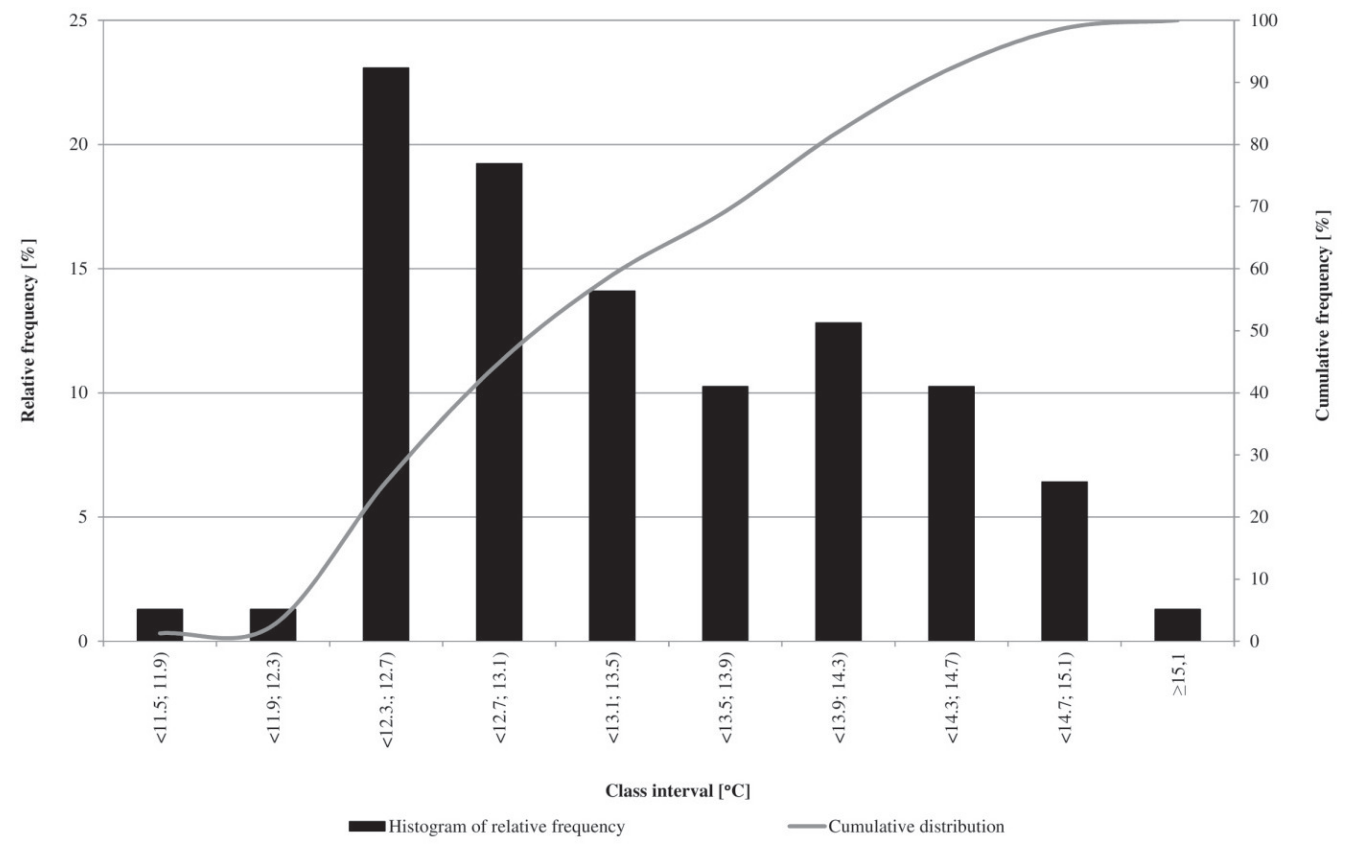

Fig. 3. Histogram of relative frequency and empirical cumulative distribution function for soil temperature of the Mątny River catchment. 
Moderate levels of EC variability were also reported by Naynaka et al. [31], similarly to our findings for the Matny stream catchment. Soil moisture content was the highest in meadow soils. Moreover, $V_{s}$ values varied depending on the type of land use. Skewness values suggested left-side distribution of this parameter for forests and arable lands and right-side distribution for meadow areas. Platykurtic distribution was indicated only for forests. Similar results for soil moisture content variability were reported for arable lands [32]. $V_{s}$ values reflecting moisture content variability were assessed at $31 \%$, whereas the coefficient of variation for arable lands in the Mątny stream catchment was about $33 \%$.

\section{Histogram of Relative Frequency and Empirical Cumulative Distribution Function}

The next step of the analysis was the preparation of frequency histograms and empirical distribution functions for the investigated soil properties in the Matny stream catchment. The number of class intervals and their range were determined from equations 2 and 3. Frequency of

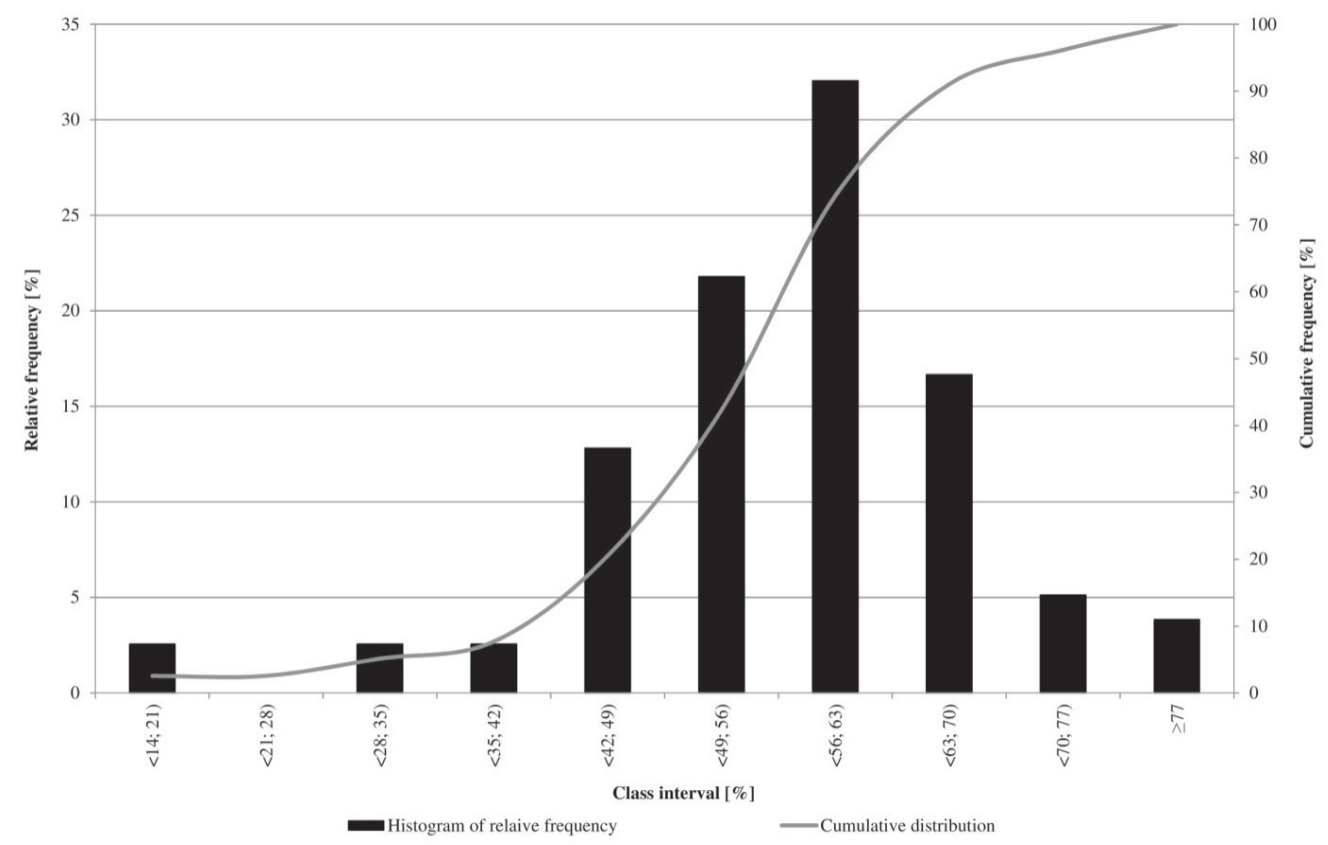

Fig. 4. Histogram of relative frequency and empirical cumulative distribution function for EC of the Mątny River catchment.

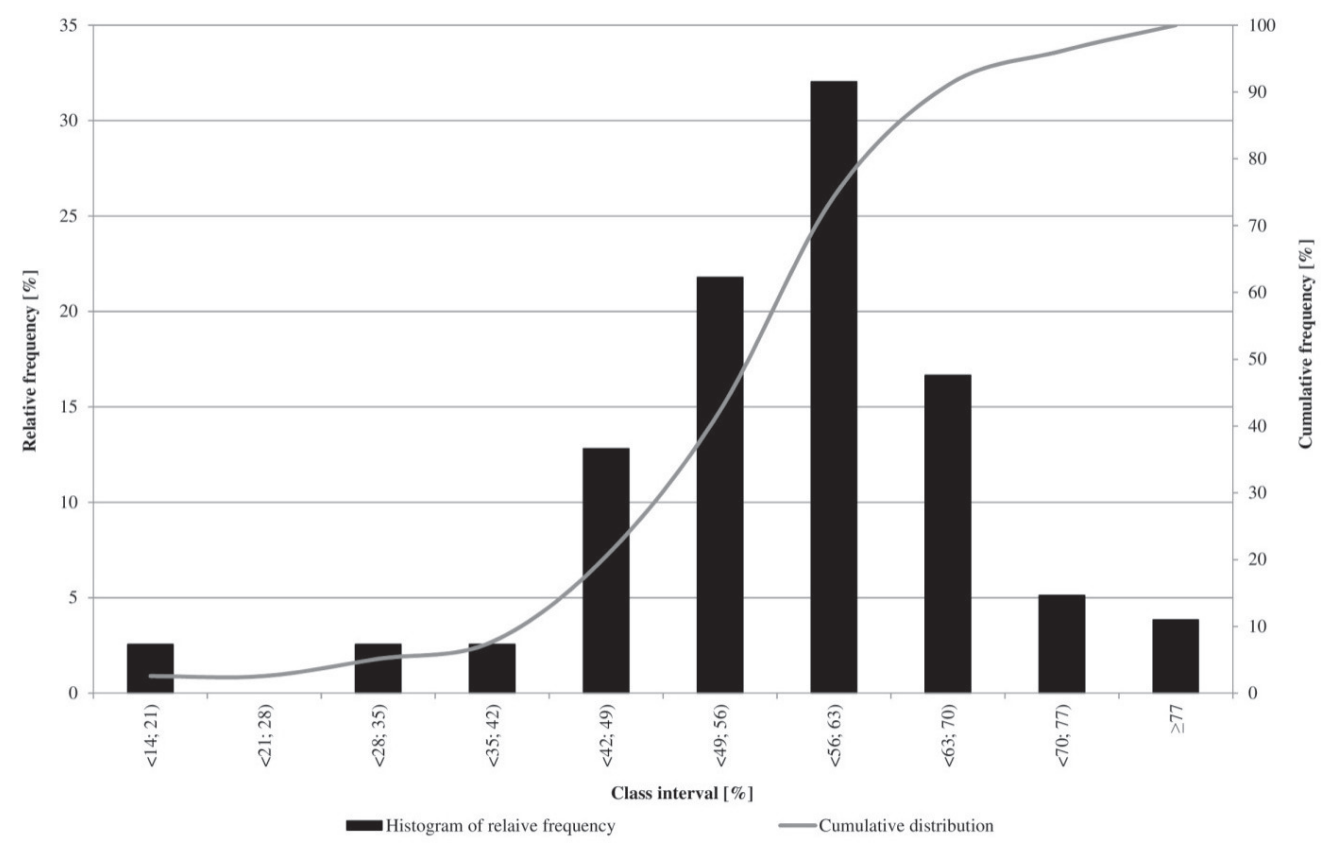

Fig. 5. Histogram of relative frequency and empirical cumulative distribution function for soil moisture of the Mątny River catchment. 
Table 2. Values of $\chi 2$ and test probability $\mathrm{P}$ determining the effects of land use on the investigated soil properties.

\begin{tabular}{|c|c|c|}
\hline Soil indicator & $\chi 2$ & $\mathrm{P}$ \\
\hline Bulk density & 23.86 & $<\mathbf{0 . 0 0 0 1}$ \\
\hline Soil temperature & 6.56 & $\mathbf{0 . 0 4}$ \\
\hline EC & 3.93 & 0.14 \\
\hline Soil moisture & 11.68 & $\mathbf{0 . 0 0 3}$ \\
\hline
\end{tabular}

specific values of the investigated soil parameters together with their empirical distribution functions are presented in Figs 2-5.

Frequency histograms and empirical distribution functions are commonly used for describing the frequency of selected soil properties [33-34]. Data presented in Fig. 2 showed that the prevailing values of bulk density ranged from 1.39 to $1.43 \mathrm{~g} \mathrm{~cm}^{-3}$. Values belonging to this interval were recorded in 33 measurements, i.e., nearly $45 \%$ of all observations. Soil temperature (Fig. 3) values fell into the class interval of 12.3 to $12.7^{\circ} \mathrm{C}$, which harbored 18 measurements (23\% of all observations). Fig. 4 shows that salinity ranged from 0.4 to $0.5 \mathrm{dS} \mathrm{m}^{-1}$. This indicated sufficient agricultural usefulness of the study area. Values belonging to this interval were recorded in 35 measurements, or nearly $45 \%$ of all observations. The data in Fig. 5 indicated that soil moisture content in the investigated catchment fell within a $56 \%$ to $63 \%$ interval for $32 \%$ of all measurements. The highest dispersion of the soil properties was noticed for soil moisture content. This was evidenced by the coefficient of variation that indicated distinct differences in variability for this parameter.

\section{Impact of Land Use on Soil Properties}

The outcomes of the Kruskal-Wallis test showed that the type of land use significantly affected soil properties, such as bulk density, soil temperature, and moisture content (Table 2). This was evidenced by the values of test probability $\mathrm{p}$ that for these parameters was lower than the assumed level of significance $\alpha=0.05$. Therefore, there was no reason to accept hypothesis $\mathrm{H}_{0}$ that assumed no significant differences in specific values of the investigated variables. Contrary to the above, land use did not affect salinity values. This may be explained by the fact that salinity caused by natural factors is strictly local and that its main sources are anthropogenic, i.e., mineral fertilizers. Similar results were published by other authors [35-36], who also demonstrated a significant effect of land use on selected physical and chemical properties of soils in the investigated areas. Moreover, soil properties are commonly used in the analysis of the impact of selected factors on soil quality [37-45].

\section{Artificial Neural Networks}

Verifying ANN performance has gained widespread application in environmental engineering [46]. The bestperforming network was the three-layer MLP (a multilayer perceptron) for soil temperature with a logistical function of hidden neuron activation and hyperbolic tangent for the output neurons. MLP was also selected as an artificial neural network for EC, and it featured the exponential activation function of the hidden neurons and linear activation function of the output neurons (Table 3). In modeling engineering problems for environmental purposes the optimization of activation function should be applied to improve ANN with satisfactory results [47]. The value of EC was mainly affected by soil moisture content, soil texture, soil temperature, and bulk density (MPE, mean percentage error was $2.35 \%$ ). Temperature was mainly dependent on EC, soil moisture content, and bulk density (MPE = 7.97). A prognosis for the type of land use for both parameters was heavily error-burdened. The error threshold was assumed as $10 \%$ relative error commonly used in simulation research [48].

\section{Analysis of Spatial Model}

Classic spatial autocorrelations are statistical comparisons of spatial weights with covariance relationships for two locations. Spatial autocorrelation determines a degree of relationship between spatial units [49]. Positive spatial autocorrelation was found for EC, suggesting that EC accumulation depended on the environment in which it occurred (Fig. 6a). Positive autocorrelation means spatial accumulation of high or low values of the observed variables. Positive autocorrelation was also determined for soil temperature (Fig. 6b). When the spatial autocorrelation is more positive than expected based on random data, it indicates a grouping of similar values in the entire geographic space. Such a high correlation signals high spatial ordering of the investigated variable. The presence of positive spatial autocorrelation leads to an underestimation of the appropriate sample size [50]. Our study area featured well-defined clusters of zones with high or low temperatures. This was probably due to

Table 3. Artificial neural network (topography according to MLP 5-5-1).

\begin{tabular}{|c|c|c|c|c|c|}
\hline \multirow{2}{*}{ Variables } & \multicolumn{3}{|c|}{ Quality } & \multicolumn{2}{c|}{ Activation function of a node } \\
\cline { 2 - 6 } & Learning & Verification & Validation & Input & Output \\
\hline Soil temperature & 0.75 & 0.35 & 0.73 & Logistic & Hyperbolic tangent \\
\hline EC & 0.80 & 0.59 & 0.87 & Exponential & Linear \\
\hline
\end{tabular}




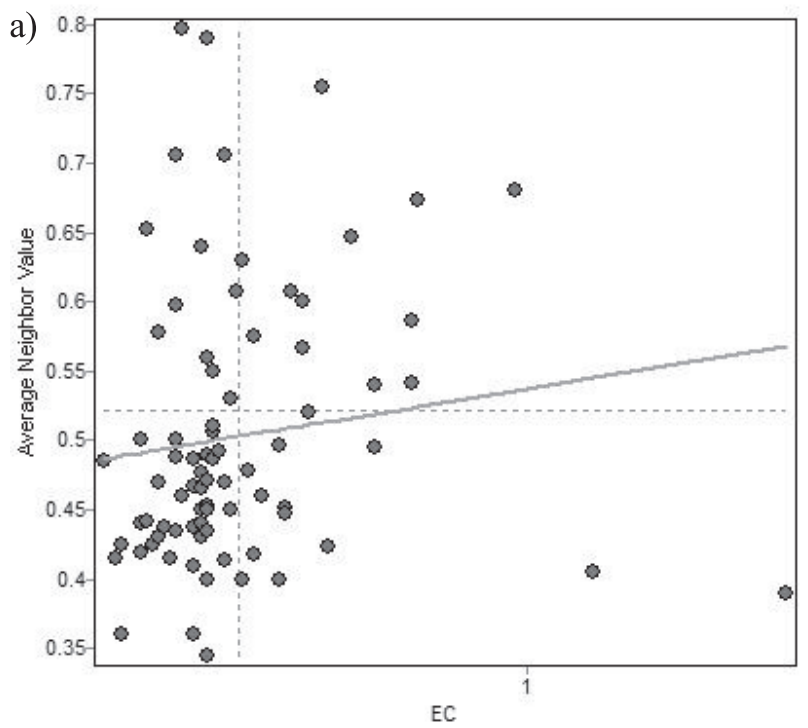

b)

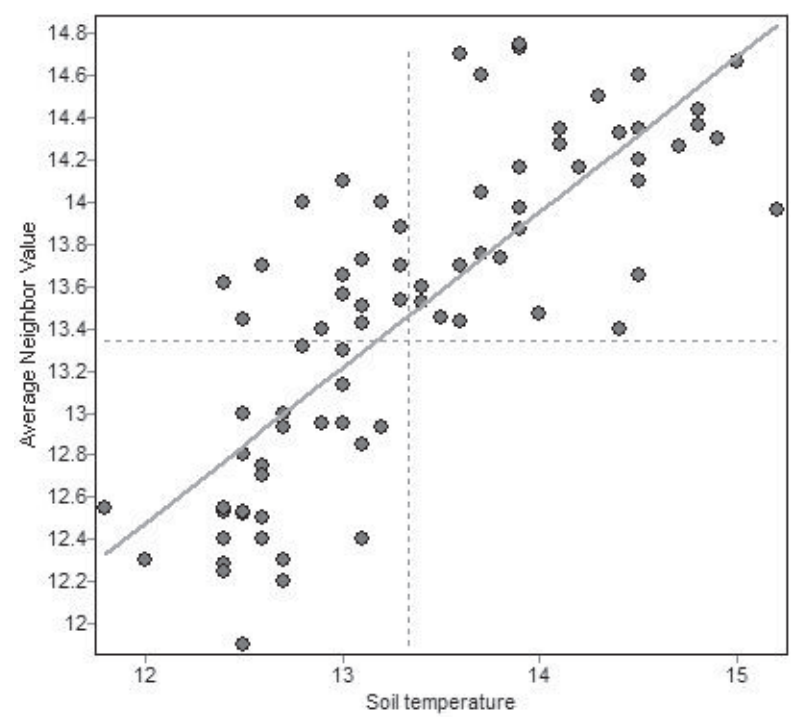

Fig. 6. Correlogram present spatial positive autocorrelation for a) $\mathrm{EC}$ and b) soil temperature.
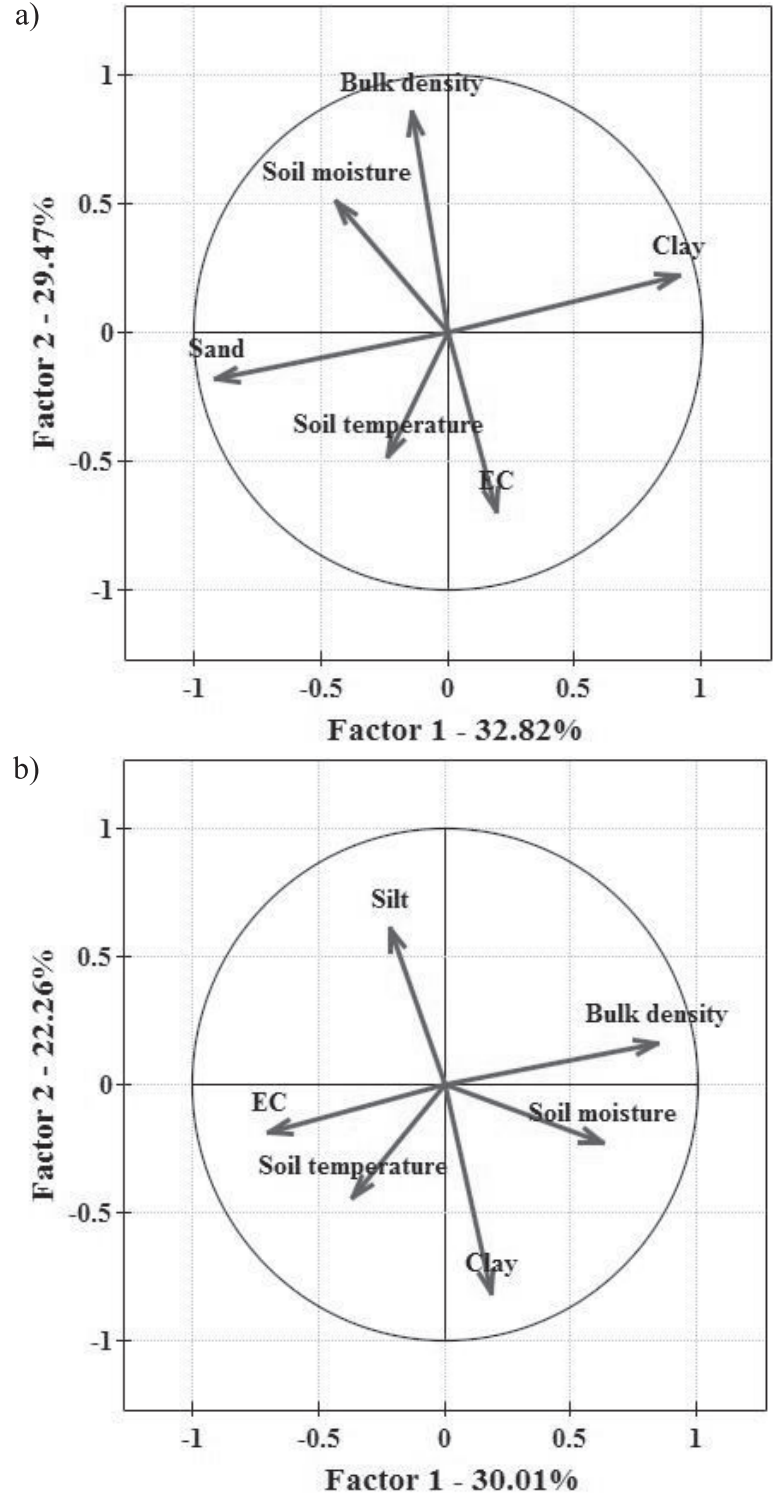

Fig. 7. PCA showed the most important factors in catchment designed for a) agriculture-use and b) forest zone.

Table 4. Results of Simultaneous Autoregression for EC and soil temperature computed with predictor variables. Significant value are bolded.

\begin{tabular}{|c|c|c|c|c|c|}
\hline Variable & Coefficient value & Standard Coefficient & Standard Error & $\mathrm{t}$ & $\mathrm{P}$ \\
\hline \multicolumn{6}{|c|}{$\mathrm{EC}$} \\
\hline Constant & 9.28 & - & 5.30 & 1.75 & 0.08 \\
\hline Bulk density & -6.20 & -0.27 & 2.91 & -2.12 & 0.037 \\
\hline Soil moisture & 0.009 & 0.078 & 0.01 & 0.63 & 0.52 \\
\hline \multicolumn{6}{|c|}{ Soil temperature } \\
\hline Constant & 1.19 & - & 1.79 & 0.66 & 0.91 \\
\hline $\mathrm{EC}$ & 0.04 & 0.012 & 0.42 & 0.10 & 0.51 \\
\hline Bulk density & 0.12 & 0.012 & 1.27 & 0.09 & 0.92 \\
\hline Soil moisture & -0.02 & -0.45 & 0.006 & -4.006 & $<0.01$ \\
\hline
\end{tabular}


differences in location of these zones and their different exposures. Higher temperatures were recorded on the slopes with southern exposure (S). This relationship causes spatial grouping of similar values into clusters and allows for identification of spatial agglomeration effects, i.e., its significant values indicate whether there are clusters of similar-high or low-values around a spatial unit. The larger scale indicated high autocorrelation and agglomeration in multi-scale spatial autocorrelation analysis of cultivated land quality [51]. Fig. 6 shows the results for Moran's correlation coefficients for EC and soil temperature.

The spatial autoregressive model for EC demonstrated the greatest role of bulk density $(\mathrm{p}<0.05 ; \mathrm{r}=0.24)$. Spatial effect coefficient (rho) was 0.96 (standard error $=3.81$ ). Estimation according to Akaike's Information Criterion for small samples (AICc) yielded the value of 8.62. Spatial autoregression for temperature indicated soil moisture content as the best predictor for spatial modeling $(\mathrm{p}<0.01$; $r=0.45$ ). The spatial effect coefficient was 0.97 (standard error $=0.16$; AICc $=110.34$ ). Detailed results for the model of the investigated variables in the spatial arrangement are presented in Table 4.

In an agricultural area, estimation of soil parameters might be indicated based on multivariate analysis. In our research for both types of land use, soil temperature negatively correlated with the factors determined by principal axes. In arable lands, clay showed a positive correlation for the major component of both the first and second primary axis (Barlett test $\mathrm{p}<0.01$; KMO coefficient $=0.42$ ). In forest zones, the most prominent factor was bulk density (Barlett test $\mathrm{p}<0.01$; KMO coefficient $=0.45$ ), which positively correlated with both principal components presented by ordination technique (Fig. 7).

\section{Conclusions}

Soil parameters such as EC, temperature, moisture content, and bulk density with soil texture are suitable for soil quality assessment. EC and soil temperature are important parameters but they show positive autocorrelation. The factors affecting EC and temperature (moisture content, bulk density, land use, and soil texture) may be analyzed by means of ANNs. The most useful factors in modeling EC were soil temperature and soil texture, and for modeling soil temperature the most important parameters were soil moisture content and bulk density. The MLP neural network model for both EC and temperature showed that land use variable was heavily burdened with error when used for forecasting these parameters. However, the evaluation of land use effects on the changes in the investigated soil properties revealed that EC was the only variable unaffected by land use. This was due to the very small reach of natural sources of salinity. Multivariate analysis indicted differences between the types of land use. Arable lands were most seriously affected by the share of clay, and the most important factor in forests was bulk density. Further studies focusing on variability of specific soil properties should be carried out to confirm agricultural productivity of these soils, and to improve their qualities that are important for agricultural productivity and ecosystem services (e.g., C sequestration).

\section{Acknowledgements}

This research was financed by the Ministry of Science and Higher Education of the Republic of Poland (within the framework of research projects for young scientists; No. of subject: BM-4392-KMiKŚ/2016, name of subject: Seasonal variability of the nitrates and phosphates loads in Smugawka Stream in Beskid Wyspowy (Western Carpathians); No. of subject: BM-4387/KISiGW/2016, name of subject: Verification of selected empirical formulas to calculate flood frequency in catchments of upper Vistula basin), and by statutory activity of the Department of Land Reclamation and Environmental Development as well as the Department of Sanitary Engineering and Water Management.

\section{References}

1. HALECKI W., GĄSIOREK M., GAMBUŚ F., ABRAM R. The potential of hydrated and dehydrated sewage sludge discharges from soil reclamation appliances. Fresenius Environmental Bulletin, 25 (6), 1935, 2016.

2. HANI A., PAZIRA E., MANSHOURI M., BABAIE KAFAKY S., GHAHROUDI TALI M. Spatial distribution and mapping of risk elements pollution in agricultural soils of southern Tehran, Iran. Plant Soil Environment, 56, 288, 2010.

3. USOWICZ B., HAJNOS M. SOKOŁOWSKA, Z. JÓZEFACIUK G. BOWANKO G. KOSSOWSKI J., USOWICZ J. Variability of soil characteristics in the field scale and Villages. Annals of Soil Science, 1, 237, 2004.

4. DUFFKOVÁ R., MACUROVÁ H. Soil biological quantity and quality parameters of grasslands in various landscape zones. Plant Soil Environment, 57, 577, 2011.

5. WEIDORF D. C., ZHUY., Spatial variability of soil properties at Capulin Volcano, New Mexico, USA: Implications for sampling strategy. Pedosphere, 20, 185, 2010.

6. KROULIK M., KUMALA F., MIMRA M., PRASEK V. Possibilities for determination of interdependence between soil properties and yield. Ag. Eng. Leuven 2004. Book of abstracts, 80, 2004.

7. SCHUTTE B., KUTZBACH H. D. Tillage draught force as information source for soil variability. Ag. Eng. Leuven 2004. Book of abstracts, 54, 2004.

8. WYSZKOWSKA J., BOROS E., KUCHARSKI J. Effect of interactions between nickel and other heavy metals on the soil microbiological properties. Plant Soil Environment, 53, 544, 2007.

9. WANG Y., Q., SHAO M.A. Spatial variability of physical properties in a region of the Loess Plateau of PR China subject to wind and water erosion. Land Degradation and Development, 24 (3), 296, 2013.

10. ADHIKARI P., SHUKLA M.K., MEXAL J. Spatial variability of electrical conductivity of desert soil irrigated with treated wastewater: implications for irrigation 
management. Applied and Environmental Soil Sciences, 2011, 1, 2011.

11. BOROWIK A., WYSZKOWSKA J. Soil moisture as a factor affecting the microbiological and biochemical activity of soil. Plant Soil Environment, 6, 250, 2016.

12. USOWICZ B., REJMAN J. Spatial distribution of topsoil water content along a loess hillslope transect. Acta Agrophysica, 35, 201, 2000.

13. BASHA G., OUARDA T., MARPU P.R. Long-term projections of temperature, precipitation and soil moisture using non-stationary oscillation processes over the UAE region. International Journal Climatology, 35, 4606, 2015.

14. LEHNART M. Factors affecting soil temperature as limits of spatial interpretation and simulation of soil temperature. AUPO Geographica, 45, 5, 2015.

15. IMRAN M., ASHRAF A., REHMAN A.U. Soil Electric Conductivity using Bayesian Kriging - A case study from Qasur, Pakistan. Journal of the Geological Society of India 88, 711, 2016.

16. MOKARRAM M., SATHYAMOORTHY D. Investigation of the relationship between landform classes and electrical conductivity (EC) of water and soil using a fuzzy model in a GIS environment. Solid Earth, 7, 873, 2016.

17. CORWIN D. L., LESCH, S. M. Characterizing soil spatial variability with apparent soil electrical conductivity I. Survey protocols. Comput. Electron. Agr., 46,103, 2005.

18. WANG LI., ZHAO Q., ZHANG Y., ZHOU Q. In Situ Representation of Soil/Sediment Conductivity Using Electrochemical Impedance Spectroscopy. Sensor, 16, 1, 2016.

19. HILLEL D. The soil in the environment. Publ. PWN, 386, Poland, 2012.

20. MOCEK A., DRZYMAŁA S. Genesis, analysis and classification of soils. Publ. UP Poznan, 418, Poland, 2010.

21. LAI R., ARCA P., LAGOMARSINO A., CAPPAI C., SEDDEAIU G., DEMURTAS C. E., ROGGERO P. P. Manure fertilization increases soil respiration and creates a negative carbon budget in a Mediterranean maize (Zea mays L.)-based cropping system. Catena, 151, 202, 2017.

22. RYCZEK M. Forecasting the intensity of suspended sediment transport in small mountain streams of the Western Carpathians using physiographic catchment. Publ. Univeristy of Agriculture, Poland, 2011.

23. RYCZEK M., BOROŃ K., KLATKA S., KRUK E. Use of GIS technics for evaluation of water erosion threat on example of the Matny river basin in the Beskid Wyspowy. Scientific Journal of Wrocław University of Environmental and Life Sciences, 576, 175, 2010.

24. HALECKI W., MŁYŃSKI D., RYCZEK M., KRUK E., LIS J. Spatial variability of soil moisture and bulk density in the mountainous catchment of the Mątny river located in the Gorce. Episteme, 30, 347, 2016 [In Polish].

25. MUCHA J. Geostatistical methods in documenting deposits. Script. Publ. AGH, 194, Poland, 1994.

26. KRUSKAL W. H., WALLIS W. A. Use of Ranks in OneCriterion Variance Analysis. J. Am. Stat. Assoc., 47, 583, 1952.

27. OLUSANYA E., OLUBUSOYE E. O., OKUNLOLA O. A., KORTER O. G. Estimating Bias of Omitting Spatial Effect in Spatial Autoregressive (SAR) Model. International Journal of Statistics and Applications, 5, 150, 2015.

28. RANGEL T.F.L. V. B, DINIZ-FILHO J.A.F., BINI L.M. SAM: a comprehensive application for Spatial Analysis in Macroecology. Ecography, 33, 46, 2010.

29. MZUKU M., KHOSLA R., REICH R., INMAN D., SMITH F., MCDONALD L. Spatial variability of measured soil properties across site-specific management Zones. Soil Sci. Soc. Am. J., 69, 1572, 2005.

30. KILIC K., KILIC S., KOCYIGIT R. Assessment of spatial variability of soil properties in areas under different land use. Bulg. J. Agric. Sci., 5, 722, 2012.

31. NAYANAKA V.G.D., VITHARANA W.A.U., MAPA R.B. Geostatistical analysis of soil properties to support spatial sampling in a paddy growing Alfisol. Trop. Agric. Res. 22, 34, 2010.

32. MOLIN P.J., FAULIN G.C. Spatial and temporal variability of soil electrical conductivity related to soil moisture. Sci. Agr., 1, 1, 2013.

33. WALTER C., MCBRATNEY A.B., DOUAOUI A., MINASNY B. Spatial prediction of topsoil salinity in the Chelif Valley. Algeria. using local ordinary kriging with local variograms versus whole-area variogram. Aust. J. Soil Res, 39, 259, 2001.

34. BRULAND G.R., RICHARDSON C.J., WHALEN S.C. Spatial variability of denitrification potential and related soil properties in created restored and paired natural wetlands. Wetlands, 4, 1042, 2006.

35. DUGUMA L.A., HARGER H., SIEGHARDT M. Effects of land use types on soil chemical properties in smallholder farmers of central highland Ethiopia. Ecology, 1, 1, 2010.

36. KIFLU A., BEYENE M. Effects of different land use systems on selected soil properties in South Ethiopia. J. Soil Sci. Environ. Manage, 4, 100, 2013.

37. GRUBA P., SOCHA J., BŁOŃSKA E., LASOTA J. Effect of variable soil texture, metal saturation of soil organic matter (SOM) and tree species composition on spatial distribution of SOM in forest soils in Poland. Science of The Total Environment, 521-522, 90, 2015.

38. SUNG E.C., HYUNG C.P. Effect of spatial variability of cross-correlated soil properties on bearing capacity of strip footing. Numerical and Analytical Methods in Geomechanics, 34, 1, 2010.

39. POGGIO L., GIMONA A., BREWER M.J. Regional scale mapping of soil properties and their uncertainty with a large number of satellite-derived covariates. Geoderma, 209-210, $1,2013$.

40. JANGID K., WILLIAMS M.A., FRANZLUEBBERS A.J., SCHMIDT T.M., COLEMAN D.C., WHITMAN W.B. Land-use history has a stronger impact on soil microbial community composition than aboveground vegetation and soil properties. Soil Biology and Biochemistry, 43, 2184, 2011.

41. JORDAN A., ZAVALA L.M., GIL J. Effects of mulching on soil physical properties and runoff under semi-arid conditions in southern Spain. Catena, 81, 77, 2010.

42. LU A., WANG J., QIN X., WANG K., HAN P., ZHANG S. Multivariate and geostatistical analyses of the spatial distribution and origin of heavy metals in the agricultural soils in Shunyi, Beijing, China. Science of The Total Environment, 425, 66, 2012.

43. ZHAO X., WU P., GAO X., PERSAUD N. Soil Quality Indicators in Relation to Land Use and Topography in a Small Catchment on the Loess Plateau of China, Land Degradation \& Development, 26, 54, 2015.

44. YU Y., WEI W., CHEN L.D., JIA F.Y., YANG L., ZHANG, H.D., FENG T.J. Responses of vertical soil moisture to rainfall pulses and land uses in a typical loess hilly area, China, Solid Earth, 6, 595, 2015.

45. LAISKHANOV U.S., OTAROV A., SAVIN Y.I., TANIRBERGENOV I.S., MAMUTOV U.Z., DUISEKOV N.S., ZHOGOLEV A. Dynamics of Soil Salinity in 
Irrigation Areas in South Kazakhstan. The Polish Journal of Environmental Studies, 25, 2469, 2016.

46. AZADI S., KARIMI-JASHNI A. Verifying the performance of artificial neural network and multiple linear regression in predicting the mean seasonal municipal solid waste generation rate: A case study of Fars province, Iran. Waste Management, 48, 14, 2016.

47. DEMIR S., KARADENIZ A, DEMIR M.N. Using Steepness Coefficient to Improve Artificial Neural Network Performance for Environmental Modeling. The Polish Journal of Environmental Studies, 25 (4), 1467, 2016.

48. YANG J., GONG W., SHI S., DU L., SUN J., SONG S.L. Estimation of nitrogen content based on fluorescence spectrum and principal component analysis in paddy rice. Plant Soil Environment, 62,178, 2016.
49. MATHUR M., SUNDARAMOORTHY S. Spatial Autocorrelation and its Relationships with Community Dynamics, Soil and Site quality factors: A study from Arid desert with Different Magnitudes of Resource Pulses. International Journal of Plant Research 29, 41, 2016.

50. MORRIS E.S, THAKAR V., GRIFFITH D.A. RespondentDriven Sampling and Spatial Autocorrelation. Advances in Geocomputation, 22, 241, 2016.

51. LI W., ZHU C., WANG H., XU B. Multi-scale spatial autocorrelation analysis of cultivated land quality in Zhejiang province. Transactions of the Chinese Society of Agricultural Engineering, 32, 239, 2016. 